\title{
Health care needs of older people living permanently in a residential home setting in Gauteng
}

\author{
MM Chabeli, Department Of Nursing, Rand Afrikaans University
}

\begin{abstract}
This article reviews some of the prevailing health needs of elderly people living permanently in a residential old age home. A qualitative, exploratory and descriptive design was employed. Twenty-one black elderly people were purposively selected to participate in a focus group interview session for the purpose of describing their perception of their health care needs. From descriptive content analysis, three main data sets emerged, namely physical health needs, unmet psychological needs and the need for a healthy social relationship. Recommendations to deal with these health needs were made based on the empirical data supported by literature. Measures of trustworthiness were ensured as described by Lincoln and Guba (1985:316-327).
\end{abstract}

\section{Abstrak}

Hierdie artikel kyk na die algemene gesondheidsbehoeftes van bejaardes wat permanent in "n ouetehuis bly. ' $n$ Kwalitatiewe, verkennende en beskrywende ontwerp is gebruik. Een en twintig swart bejaarde persone is met ' $n$ bepaalde doel geselekteer om aan ' $n$ fokusgroeponderhoudsessie deel te neem, naamlik om hul persepsie met betrekking tot hulle gesondheidsorgbehoeftes te beskryf. Uit die beskrywende inhoudontleding het drie stelle hoofdata na vore gekom, naamlik: die fisiese gesondheidsbehoeftes, onbevredigde sielkundige behoeftes en die behoefte aan'n gesonde sosiale verhouding. Aanbevelings om die behoeftes te hanteer is gedeen gegrond op die empiriese data ondersteun deur die literatuur. Betroubaarheidsmaatreëls is verseker soos wat Guba en Lincoln (1985) dit beskryf.

\section{Introduction}

The old age home in question was established in 1988 in response to the concern of the community for meeting the comprehensive health care needs of the aged. The purpose of the institution is to meet the health care needs of the aged and to offer refuge to the destitute and extremely infirm elderly. Therefore, they admit and accommodate elderly people with no accommodation, who are destitute, abused and handicapped with no care giver and those who are extremely infirm.

It is traditionally an honour to have an elderly person in the family who is looked upon as a rich source of knowledge, skills and values among the black community. The presence of an elderly person enhances the dignity and respect of a family. With the current political, economic and social changes, the black community is inclined to adopt the Western culture where children take their elderly people to the nursing homes to live there permanently. They are relieved when an institution takes over the responsibility of the family, not realizing that their cooperation with the nursing staff is still very important. Some children pay them a visit, but some never do (Recitikainen in ICN, 1999:63).

This situation raises some concerns especially among the black people, who regard elderly people as the roots re- sponsible for the transmission of culturally-based knowledge, beliefs, customs and values. Older people in nursing homes generally lack family support. According to the $\mathrm{Pa}$ tients Rights Charter as guaranteed in the Constitution of the Republic of South Africa Act (Act No 108 of 1996), everyone has the right to a healthy and safe environment that will ensure their physical, mental and social well-being. They have rights of access to health care services that include a positive disposition displayed by health care workers who demonstrate courtesy, human dignity, patience, empathy and tolerance.

The health-related problems that exist in old age homes are of concern to the community and the health care services as a whole. It has been projected by ICN (1996:60) that by 2020 , the population of older people in developing countries will rise by nearly $240 \%$ from the 1980 level due to a rapid decline in fertility, and there will be a longer life expectancy due to the use of advanced technology and medication. An estimation based on the 2001 census statistics in South Africa, shows that a total of $6,6 \%$ of the total population in Gauteng province to be older than 65 years. Of this total, older people who are white constitute $43,1 \%$, blacks $51 \%$, Indians $2,5 \%$ and Coloreds $3,1 \%$. Life expectancy in Africa is 52 years compared to 63 years for South African population and 74 years for the developed countries. It must be noted that the health of the entire SA popu- 
lation has improved significantly, but the black population have not yet reached their optimum life expectancy (Hattingh; Van Der Merwe; Van Rensburg \& Dreyer 1996:5758). This is evidenced by the overcrowded old age homes, so much so that most of the elderly people cannot be accommodated in the institutions and they are therefore left with no choice but to live with their families. According to the researcher's observation family members sometimes lock the elderly people in the house when they go to work since they have no one to care for them.

The health needs of elderly people living permanently in a specific old age home became a concern of a nursing department at a university in Gauteng. A project was initiated in 1998 where post-basic nursing students doing community nursing science undertook a project to provide 'service learning' to the elderly people by performing physical examinations, giving health education and physical exercises. The identified problems were referred to the doctor at a nearby clinic. This prompted the need for research to explore the heaith needs as perceived by the elderly people themselves and to make recommendations to deal with the problems outlined.

Elderly people are prone to develop age-related physical, psychological and emotional conditions. They have poor functional disabilities, dementia and the lack of family support (Reconstruction and Development Programme, 1994). There is a real need for students placement opportunities to carry out constant physical examinations and provide psychological and emotional support to meet these healthrelated problems and to elevate their morale (Lockey, 1999:21).

The purpose of the study was to conduct qualitative, exploratory and descriptive research that would establish the perceived health needs of the older people living permanently in an old age home with the aim of making recommendations for dealing with these health problems. The following research question was used to guide the study: "What are the health care needs of the aged living permanently in an old age home and how could nurses meet these health care needs?'.

To meet the purpose of the study, the following research objectives were realised:

- To explore and describe the health needs of the aged living permanently in an old age home in Gauteng.

- $\quad$ To make recommendations to meet the perceived health care needs of the aged living in an old age home.

\section{Terminology}

Some confusion arises from terms used outside the context within which they are defined. The terms health, health care needs, older people and old age home are relevant to the study.

\section{Health}

The good health of an older person is defined in terms of the ability to function autonomously within a given social setting. If socially and intellectually active, the older person may be considered healthy even in the presence of chronic disease. The health of an older person is best measured in terms of function rather than pathology (ICN, 1999: 60).

\section{Health care needs}

A need has been defined as an individual ability to benefit from a specific health care intervention (Steven and Roberts in Vernon, Ross \& Gould, 2000:284). Health care needs are potentially limitless, especially when competing for stretched resources and evidence- based care within a primary health care approach.

\section{Older people}

People who cross the 60 -year threshold are regarded as older people, with the proposal that 65 years and older is the norm for old age. The age composition in our society is changing at the same rate or at an even faster rate in the future (ICN 1999: 60; Hattingh et al 1996:56).

\section{Old age home}

This is an institution where older people are cared for. The goal of this care is to assist older people in achieving optimal health, well-being and quality of life, as determined by those receiving care or consistent with the values and known wishes of the individual (ICN, 1999: 61). It is an institution established and registered to provide accommodation to, and care of, aged or debilitated people (Aged Persons Act, Act No 81 of 1967 - as amended).

\section{Research method}

An exploratory, descriptive, qualitative design was used to explore the health care needs of elderly people living permanently in an old age home in Gauteng (Mouton \& Marais, 1990:32). The old age home consists of 97 elderly people 75 of whom are women and 22 are men. Their ages range from 60 years to 100 years with a mean of 74 . Some have lived in the old age home for 14 years.

A student facilitator, who is an elderly person herself, purposively selected a sample of 21 elderly women and 6 men. The selection was made from those classified in group one, that is, those who are healthy and independent. This made the collection of data far more enjoyable as someone of their age group who understood their health care needs better conducted the focus group interview. The participants were requested permission to participate in the study a day before the interview and verbal consent was obtained. Written permission was also obtained from the management committee of the institution. A tape recorder was used with their permission. Three people were involved in the data collection. Two facilitators who were of the participants' age group, one of them led the focus group interview. Another facilitator helped with the clarification of questions and the exploration of responses in order to obtain in-depth information while using humour to ease the climate. The researcher's role was to gather as many field 
notes as possible to enrich the data. The following criteria were used to determine eligibility for participation in the study:

- 60 years and older;

- healthy;

- able to communicate freely in own language;

- $\quad$ orientated with regard to person, time and place; and

- $\quad$ complete voluntary participation.

The participants were informed that they could refuse or refrain from answering the questions at any time. They were assured of confidentiality and anonymity. The central research question asked was: "What are your health care needs as residents of this home and how could nurses who come on Thursdays meet these needs?' The interviews lasted for 2 hours and 30 minutes due to the relaxed atmosphere which included humor. Data was collected until saturation was reached. The data was analysed by using the open coding method of qualitative data analysis as described by (Tech's in Creswell 1994:154-155). The two tapes were transcribed verbatim and translated into English by the two facilitators. An external coder, who was also purposively selected, was requested to analyse the data using the same protocol. Lincoln and Guba's (1985:316327) method of ensuring trustworthiness was used in accordance with the four principles, namely credibility, transferability, dependability and conformability.

\section{Results}

Three main categories and sub-categories emerged as follows: physical health needs,

psychological needs and healthy social relationships, as indicated in table 1.

Table 1. Health care needs of older people living permanently in an old age home

\begin{tabular}{|l|l|l|}
\hline PHYSICAL NEEDS & PSYCHOLOGICAL NEEDS & SOCIAL RELATIONSHIPS \\
\hline Constipation & Depression & Ubuntu \\
\hline Sleeplessness & Loss of trust & \\
\hline Lack of appetite & Memory loss & \\
\hline $\begin{array}{l}\text { Chronic diseases } \\
\text { (asthma, hypertension, } \\
\text { arthritis) }\end{array}$ & Fear, anger & \\
\hline Visual problems & Irritability & \\
\hline
\end{tabular}

\section{Physical health care needs}

Community health nursing students are placed in old age homes for their experiential learning. They provide health care services, such as physical assessment, and they make referrals to the doctor at a nearby clinic under the supervision of the facilitator. Surprisingly, most of the participants indicated that they had varied physical problems that are not identified and treated, such as constipation, insomnia, lack of appetite and chronic diseases. The following citations indicated the participants' perceptions: "At present my major problem is my tummy. I am always constipated. Nurses will always say that I must drink lots of water and exercise so that my tummy can be loose, but they will not show me how to do it. I am tired of people just talking".

"The constipation has given me piles in that my whole body is affected."

"Yes, I need help because I eat well but I am unable to pass a stool. What helps me is the muti from the veld that I got".

"I have no appetite, and this is how I live."

"I have been suffering for a long time now. I was told that I have asthma, rheumatism, high blood pressure...eh!... there is no illness that I have not suffered from, even cramps."

"I have headaches, dizziness and backache. This is the work of a devil."

"I have no strength, I feel weak. I have poor eyesight and that is why I use a walking-stick as a pathfinder. I also cannot sleep well at night. Hawu! I become restless through the night and if I am awake I think all along."

"Please send me to a doctor who will treat my eyes and give me glasses to see. It is difficult not to be able to see. You can't do anything and you fall easily."

From the perceptions of the older people with reference to the physical care needs, there is great need to review the community health curriculum and revisit critically an effective method of clinical accompaniment. Nurse educators and practitioners need to ask several questions in this regard. Is the care of older people not taken seriously by nursing staff? It is asserted by ICN (1999:60) that the most common chronic conditions affecting older people around the world are cardiovascular disease, osteo-arthritis, diabetes, pulmonary diseases, Alzheimer's disease, sensory impairment, edutulism (toothlessness), incontinence, and psychiatric disorders such as depression and dementia. Hypertension and diabetes prevalence is rapidly increasing in the developing world and is exacerbated by the presence of persistent poverty. Ophthalmic diseases 
such as cataracts, glaucoma, trachoma and xerophthalmia underlie visual disabilities in the developing world.

Nurses should not lose sight of their role in geriatric nursing care. They should provide a wide range of health services, including health promotion, illness prevention, rehabilitation, acute/chronic care and palliative care. Achieving the older people's optimal health, well-being and quality of life is the ultimate goal of geriatric nursing (ICN, 1999:61). Geriatric nursing is increasingly acknowledged as a nursing specialty included in the basic nursing courses that equip nurses with the specific professional knowledge, skills, attitudes and values to be able to provide quality nursing care to the older generation (ICN, 1999:61)

The community nursing curriculum empowers students to provide holistic quality health care, but when it comes to the actual delivery of that care, the opposite occurs. Do nurses and staff undermine the quality of care to be given to older people? Is it that the said curriculum does not challenge students in the case of the elderly? Does the problem lie in the implementation of the said curriculum? Is it in the effective way of clinical accompaniment? Is it a question of low paid salaries, poor conditions of service and poor staffing in the old age homes? Where do we go wrong? These questions are serious and need to be addressed by management and nurses themselves.

As stated by Lockey (1999:17), low pay devalues the role of the nurse and other key workers and may have a marked effect on standards of care because it is often linked to a lack of investment in education and training, and a high staff turnover. Some institutions employ low level training personnel to provide care. Lockey states that diluting the skills mix by using cheaper and more flexible workers as a substitute for nurses has an adverse effect on the quality of care and it is not an efficient or cost-effective solution to the problem. Lockey's argument (1999:18) is that relevant authorities should offer an attractive and realistic work package, review the conditions of service, reconsider staffing levels, offer better training facilities, and support students and nursing staff in their professional development to improve the quality of care in nursing homes.

With reference to staffing, the participants indicated that most of the time it was the matron who spoke to them. When she was off duty, they were left with less experienced staff who were not supportive. Quality of care may also be affected by lack of resources: “ ... as you can see, our beds are falling down. They are old. Quality of food is poor". Lockey (1999: 18) states that $61 \%$ of nurses in nursing homes carry out a wide range of non-nursing duties and $48 \%$ of homes do not have adequate equipment such as transport to take the older people to clinics or any other referral, such as eye testing. Because of the problems experienced by the nurses, it is not surprising that many elderly people are not likely to receive the health care services they require.

Nurses are in a good position to improve the health of the elderly and should challenge and enjoy working with this group so as to anticipate their health care problems and needs, employ disease prevention strategies and promote health. The task of the nurse to care for the aged involves not only certain nursing skills, but also the distinctive needs of the aged. Elderly people have very specific needs because of their vulnerability (Bridges 2001:34). Their physical, psychological and social needs of elderly people make extreme demands on the community nurse (Nursing Act, No 50 of 1978 as amended; Hattingh, 1996:266). To meet the complex health needs of the aged, a multi-disciplinary team approach to the health care of the elderly is mandatory. Such a team approach would, among others, provide the opportunity to develop health-oriented programme, such as exercise for the elderly, to maintain their functional ability to care for themselves and remain independent. These abilities are essential to relieve ailments such as constipation and other debilitating diseases (Gonzalez \& Jirovec, 2001: 46).

Exercise is taboo among black elderly people, especially the women. It is linked to the activities of young adults. The elderly are not viewed as capable of exercising. Older women often have to take care of grandchildren (Modungwa; Poggenpeol \& Gmeiner 2000:65), and attend to church commitments (Gonzalez \& Jirovec, 2001:47). Johnson (2000:45) states, however, that exercise could improve the physiological, psychological and cognitive functioning of the aged. Young generations urge the aged to slow down and "act according to their age" while others strongly believe that the biological changes associated with aging naturally limit the ability to be physically active and to exercise (Johnson, 2000:45). However, recent research indicates that moderate exercise can retard and even reverse the aging process and improve the daily functioning of the aged (Nazarko, 1999). Whatever theories, myths and believes that exist, the value of exercise for the aged should not be underestimated (Hattingh et al, 1996:245).

A collaborative partnership between a coordinating university, other stakeholders and the old age home should not only lead to an improvement in the care of older people, but also promote a better understanding of the education and training needs of nurses working with older people. A well-established and integrated teaching team, including the 'matron' of the home, will benefit from expertise in evidence-based nursing for older people, nation and international research, teaching networks, and high level links with national policy-makers. Evidence-based training should contribute to a better understanding and foster a change in the culture of nursing older people (Johnson, 2000:45; Davies \& Jheeta, 2001: 24).

Elderly people and their families should be made aware of their rights and the procedures to follow when they are dissatisfied (Davies \& Jheeta 2001: 24). The attitude of health care workers and students should be challenged. Student nurses should be provided with effective education and training to ensure that they are equipped to deal with the specific health needs and demands of older people wherever they might be. 


\section{Psychological needs}

The main themes that emerged to demonstrate the unmet psychological needs of the older people are depression, loss of trust, forgetfulness, fear, anger and irritability. People often assume that depression, like cognitive impairment, is a normal aspect of aging. According to Hattingh et al, (1996:144,145), depression is not a normal phenomenon in elderly people. It is characterised by, over and above, a feeling of guilt, boredom, loneliness, difficulty to concentrate, forgetfulness, retarded thinking or speech, overwhelming worthlessness and helplessness, exaggerated low selfesteem or self-reproach, loss of trust, expressing a death wish and statements about the futility of life. A depressed person will communicate distress and provide answers such as "I don't know" when asked a question.

Indeed, it was sometimes difficult to get answers from the old people, as they would say "I don't know, those who want to talk can talk". Therefore, the interviewer had to probe gently through careful questioning to obtain information about their perceived health needs. Expressing their state of forgetfulness, the participants would say, "I know I look like a fool because I forget easily. You can tell me something now, but within a minute I shall have forgotten, and at night I suddenly remember". Expressing loss of trust, the participants indicated: "We can no longer trust nurses or the clinic. They give us medicines, which are not effective. We do not get help so we go and get traditional medicines from the veld and we get better. All what nurses can do is take blood pressure, temperatures and test urine. Thereafter, they will tell us not to take food with salt and we must drink lots of water. I am stopping here. I do not want to talk anymore". At this stage, the participant expressed anger and irritability. When asked how nurses could help in this regard, he stated: "I don't know. You should know how to help me. I have finished talking to you". Another participant stated: "I cannot stand noise. I feel like being alone, but oh! Sister, I am scared here".

It is stated that aggressive feelings, attitudes and behaviour lead to isolation, deprivation, abuse, distrust and disrespect of the aged. Hattingh et al $(1996: 97,99)$ advocate full psychological assessment to determine the fear of the elderly towards the institution; aggressive behaviour; sudden change in moods; talks of suicide; depression; loss of interest, respect and trust; and loss of appetite (Colin-Shaw, 1998). One should make sure that privacy is respected. Nurses should play their advocacy role and build a respecting and trusting relationship with the aged. They should be supportive and explore different situations, communications and counselling skills. However, nurses must always keep in mind that each older person has the right to make his/her own decision (Hattingh et al, 1996:222).

\section{Social relationship}

All the participants expressed their dissatisfaction and dismay at their social relationship. They indicated that they lacked "UBUNTU" and therefore did not live in harmony as evidenced by the following citations:

"There is no life in this home. Life here is unbearable. Oh!
What can 1 say?".

"Hey! It is difficult to live here. I don't know what to say. I am asking God to help me shut my mouth. People here have no morals and respect for another person. They don't speak to each other unless there are visitors".

"My life is at risk here. This person has insulted me. He is poking his finger in my eyes. I do not like it because once I can become angry, I fight. I have asked that people who are troublesome should not worry me. People do whatever they like in this place. They bang doors and we cannot have a peaceful night. Life is made out of love and respect".

When asked what could be done about this situation, they responded: "Talk to us about 'UBUNTU'. We pray everyday for God to help us, but the same thing happens again. The root cause must be addressed". Another participant indicated: "Maybe if we can be fully occupied with handwork and we do some exercises so that we are preoccupied. As it is, we sit on chairs, go for meals and come back to the chairs until we go to sleep. So we have ample time to swear and to hate each other".

According to the Parliamentary Bulletin, White Paper for Social Welfare (1997), 'ubuntu' people are people through other people, so the principle of caring for the well-being of others, and the spirit of mutual support will be fostered. Ubuntu refers to the values of "human dignity" (Asmal, 2001; James, Auerbach, Desai, Giliomee, Jordaan, Krog, Kulati, Lehoko, Leibowitz \& Tlakula 2001). The group is of the opinion that from the values of ubuntu and human dignity flow the practice of compassion, kindness, altruism and respect, which are at the very core of making schools places where the culture of teaching and the culture of learning thrive; of making them dynamic hubs of industry and achievement rather than places of conflict and pain. Ubuntu goes beyond quality, because it embodies the concept of mutual understanding and the active appreciation of the value of human difference. It requires one to know others if one has to know oneself within a multicultural environment. Ultimately, ubuntu requires one to respect others if one is to respect oneself. The need for exercise, respect, trust, physical health needs and the value of ubuntu was evident.

\section{Discussion}

The purpose of the study was to explore and describe the perceptions of elderly people living permanently in an old age home in Gauteng with regard to their health care needs. The physical, psychological and social relationship (health care needs) strongly suggested that the nurses should be in possession of specialised, professional knowledge, skills values and an attitude of humanity to provide quality geriatric care. Nurses have to act as advocates, care givers, counselors and educators, and make the difference in the health care of the aged over and above being able to provide clinical skills (ICN: 1999:61).

Nurses have the responsibility to maintain their level of competency, raise awareness and be culturally sensitive to 
create an environment that is safe, warm, friendly, caring and supportive in a creative and enjoyable manner. It must be remembered that the aged themselves, especially black women, generally have no authority to complain about their dissatisfaction with reference to their health care, probably because it is culturally embedded in them not to question authority. They will be content with the little care they receive. They rely entirely on the nurse who should act as an advocate to ensure delivery of quality health to the aged. The following recommendations are made based on the perceptions of the aged living in an old age home, supported by literature.

\section{Recommendations}

$\bullet$

Community nursing curricula should be reviewed to empower students that are relevant and culture sensitive in the care of elderly people (ICN:1999:63). There should be a collaborative partnership between a coordinating university and other stakeholders. A strong link of the old age home with university of technikons is necessary. The collaboration should not only lead to an improvement in the care of the aged, but also promote a better understanding of the education and training needs of nurses in this regard.

The primary health care principles, Batho-Pele principles, Constitution on Human Rights and the patients' rights charter should be incorporated into the curriculum.

- The family of the elderly should be regarded as the main source of support in the care of the elderly. Nurses or old age homes should not remove this integral responsibility from the family.

The university has a strong national reputation regarding research, education and community service and should therefore foster principles of 'service-learning' and continual research to address the health problems of the older people.

The mentor of nursing students should have expert knowledge, skills and values of geriatric nursing. $\mathrm{He} /$ she should have good teaching and coaching skills and be willing to teach and change the culture of nursing older people. He/she should have ongoing evaluative skills and a wider strategic thinking skills (Johnson 2000: 45).

- Nurses should refute the idea that nursing care of the elderly does not require high professional competence and is therefore associated with low pay.

Ethical and professional guidelines or principles for nurses are a good basis for evaluating the quality of care of the elderly (ICN 1999: 63).

- $\quad$ Elderly people should be educated about their right to have knowledge about themselves, the right to a good physical, psychological and social well-being. The curriculum should ensure that nurses develop skills of physical examination, psychological support, counselling, communication and interpersonal relationship skills. They should be good lis- teners, have an empathetic understanding of older people and be sensitive to their needs. Elderly people should be educated that assessment of care will be welcomed and that quality care is their right (ICN 1999:63).

- Nurses should enforce evidence-based knowledge about the health care of older people (ICN 1999: 63).

- Nurses should be sensitive to elderly people's attitudes and their needs for effective communication and meaningful relationship (Herzenberg \& Ekman, 2000:615).

- $\quad$ The old age home should be inspected several times a year by health authorities to ensure compliance with the old age act, thereby guaranteeing that the home provides adequate service (Lockey, 1999: 21).

- A strong partnership model is advocated for a holistic approach to health care for older people, as indicated in figure 1 (effective partnership model by Gravett 1987:72).

The nurse is responsible for supervising and coordinating all the services, including the human resources management team, the ophthalmologist, the dental therapist, preventive forums, mobile clinics, local authorities and nongovernmental organizations, to provide resources, transport, funding and recreational facilities. The entire team is responsible for teaching the family members and aides, and for providing physical, psychological and emotional support to older people (Hattingh, 1996: 216).

\section{Conclusion}

With the fast-changing society and the demands for quality assurance in clinical nursing education and health care practices, the quality of health care of the aged is highly challenged. The curricula should equip nurses with expert, comprehensive knowledge, skills and values to provide quality health care to older people. Nurses should also be able to establish a good working relationship with the other health care team members, including the family of the older people.

The International Council of Nurses claims that nurses have the potential to be change agents. They have the potential to influence broad debates on global ageing. Nurses have an impact on the political and social environments and can advocate for better health and health services. They should increasingly be involved in meeting the needs of the elderly and act as advocates and facilitators in policy making, including the allocation of resources within the health and social sciences (ICN, 1999: 61).

Old age homes need nurses who care and not nurses who abuse and neglect older people physically, psychologically and emotionally. Abuse is utterly unacceptable and we have to root out contributing factors such as - not enough funding, overworked staff, victim-blaming management and chance-takers (Anderson, 1999:10).

\section{Acknowledgements}

The researcher gratefully acknowledges the support of the 
Figure 1: Effective partnership model (Gravett, 1987:72)

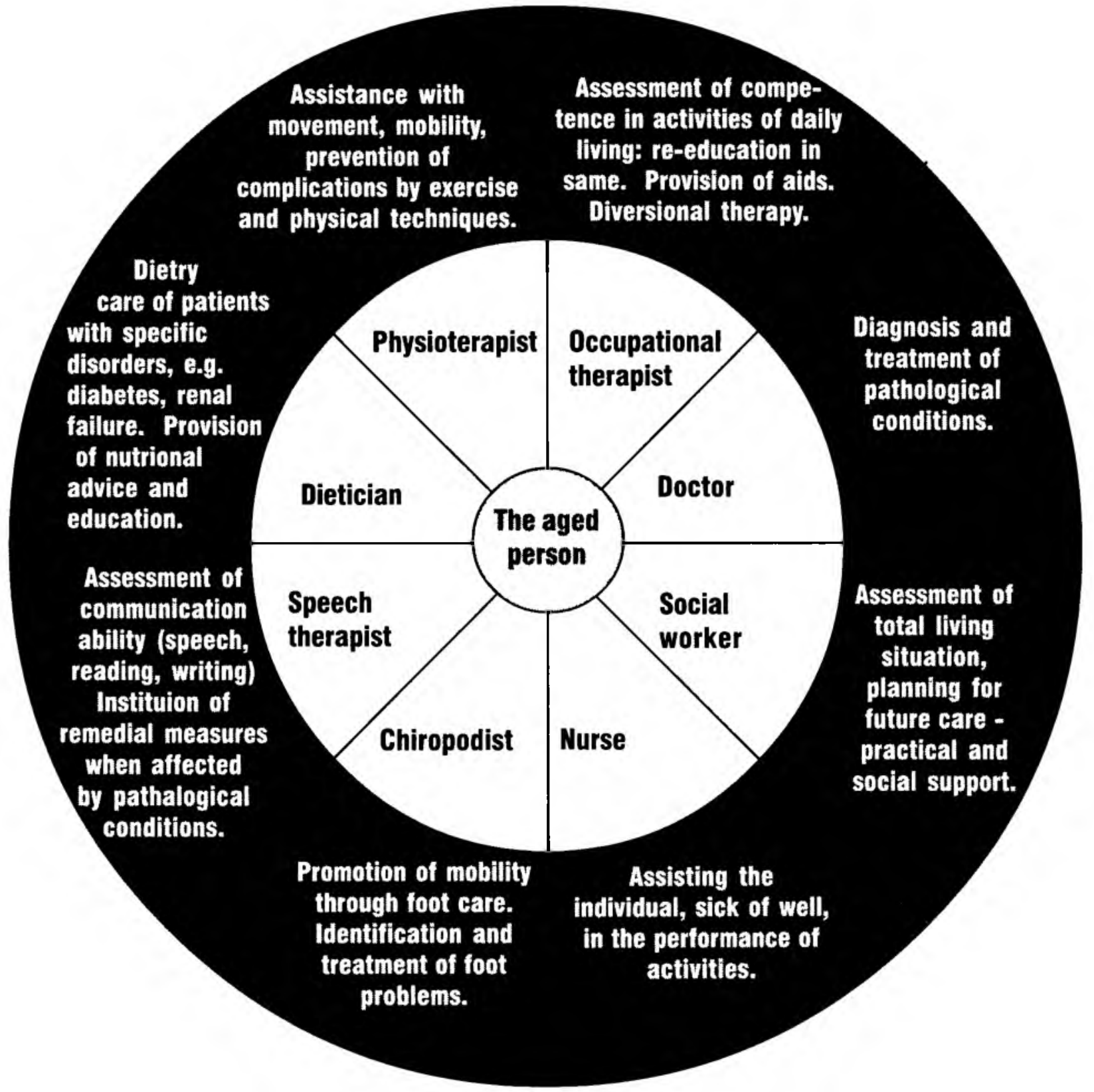

following people for data gathering.

Mrs Gugu Mmoledi, Nursing Department, RAU

Mrs lrene Maponya, Nursing Department, RAU

\section{References}

AFRICAN NATIONAL CONGRESS 1994: The Reconstruction and Development Programme (RDP), Johannesburg: Umanyano Publications.

ANDERSON, P 1999: Enough is enough. Nursing Times Nursing Homes. November - December 1(4): 9-11

ASMAL, K 2001: Manifesto on Values, Education and Democracy. July Pretoria. Department of Education.
BRIDGES, J 2001: Meeting the needs of older people in rehabilitation care. Nursing Times. January 18, 97(3): 33-34.

COLIN-SHAW, M 1998: Nursing home residents abuse by staff: exploring the dynamics. Journal of Elder Abuse. 9(4): $1-21$.

CRESWELL, JW 1994: Research Design: Qualitative and Quantitative Approach, London: Sage Publications.

DAVIES, C \& JHEETA, K 2001: Nursing blueprints for elderly care. Nursing Times. March, 97(9): 24-27.

GONZALEZ, BCS \& JIROVEC, MM 2001: Elderly Mexican women's perception of exercise and conflicting role 
responsibilities. International Journal of Nursing Studies, $38 ; 45-49$.

\section{HATTINGH,S; VAN DER MERWE,M; VANRENSBURG,} G \& DREYER, M 1996: Gerontology: A Community Health Perspective. Johannesburg: International Thompson Publishing (Southern Africa) (Pty) Ltd.

HERTZBERG, A \& EKMAN, S 2000: "We, not them and us." Views on the relationships and interactions between staff and relatives of older people permanently living in nursing homes. Journal of Advanced Nursing. 2000, 31 (3) $614-622$

JOHNSON, B 2000: Evidence-based Nursing for Older People, Nursing Times. April 20,96(16):45.

INTERNATIONAL COUNCIL OF NURSES(ICN): 1999: On health ageing: A public health and nursing challenge. International Nursing Review. 46(2): 60-63.

JAMES, W; AUERBACH, F; DESAI, Z; GILIOMEE, H; JORDAAN, P; KROG, A; KULATI, L; LEHOKO, K; LEIBOWITZ, B \& TLAKULA, P 2001: Report of the working group on values. May, 2001.

KRUEGER, RA 1994: Focus groups: A practical guide for applied research. London: Sage Publications.

LINCOLN, YS \& GUBA, EG 1985: Naturalistic Inquiry. London: Sage Publications.

LOCKEY, J 1999: The low-down on pay and conditions. Nursing Times Nursing Homes. November-December. 1(4); $17-21$.

MODUNGWA, N; POGGENPOEL, M \& GMEINER, A 2000: The experience of mothers caring for their teenage daughter's young children. Curationis, September, 24(3): 62-69.

MOUTON, T \& MARAIS, HC 1990: Basic concepts in methodology and social sciences. Pretoria: Human Sciences Research Council.

NAZARKO, L 1999: Foot Faults: Nursing Times Nursing Homes. June -July, 1(2): 17-19.

PARLIAMENTARY BULLETIN 1997: Social welfare White Paper marks major shift in welfare strategy. http:// www,anc.org.za.

SOUTH AFRICA (REPUBLIC) 2001: Census statistics. www.statssa.gov.za.

SOUTH AFRICA (REPUBLIC) 1996: The Constitution of the Republic of South Africa (Act No 108 of 1996): Pretoria: Government Printers.

SOUTH AFRICA (REPUBLIC) 1978: Nursing Act, (Act 50 of 1978 as amended) Pretoria: Government Printers
SOUTH AFRICA (REPUBLIC) 1967: Aged Person's Act, (Act No. 81 of 1967), Pretoria: Government Printers

VERNON, S; ROSS, F \& GOULD, MA 2000: Assessment of older people: politics and practice in primary care. Journal of Advanced Nursing. 3l(2), $282-287$. 